\title{
Clinical manifestations and disease activity score of rheumatoid arthritis in southeast of Iran
}

\author{
Mahnaz Sandoughi ${ }^{1}$, Mahmoud Ali Kaykhaei ${ }^{1}$, Mahnaz Shahrakipoor ${ }^{2}$, Reza Darvishzadeh ${ }^{1}$, Masoumeh \\ Nikbakht ${ }^{1}$, Sogol Shahbakhsh ${ }^{3}$ and Zahra Zakeri ${ }^{4}$ * \\ ${ }^{1}$ Department of Internal Medicine, Ali Ebne Abitaleb Hospital, Zahedan University of Medical Sciences, Zahedan, Iran. ${ }^{2}$ Department \\ of Biostatistics, Zahedan University of Medical Sciences, Zahedan, Iran. ${ }^{3}$ Medical Student, Iran University of Medical Sciences, \\ Tehran, Iran. ${ }^{4}$ Department of Internal Medicine, Shahid Beheshti University of Medical Sciences, Tehran, Iran
}

\begin{abstract}
Rheumatoid arthritis has a non-homogeneous pattern around the world. The current study aimed to describe the clinical manifestations and disease activity of rheumatoid arthritis patients in southeastern Iran. In this descriptive, cross-sectional study with convenience sampling, data regarding the demographics, painful joints, number of swollen and tender joints, ESR, disease activity, and therapeutic regimen of 500 patients with rheumatoid arthritis who referred to the Rheumatology Clinic of Ali Ebn Abitaleb Hospital between October 2012 and October 2013 was collected using a data form. After collection, the data was analyzed using SPSS version 16. Of the 500 studied cases, 437 cases (87.4\%) were female and 63 cases (12.6\%) were male. Average patient age was $48.78 \pm 13.97$ years, and the mean duration of the disease was $7.28 \pm 7.14$ years. The mean value of disease activity score-28 (DAS-28) was $3.54 \pm 1.38$. The DAS-28 in 30.25\% of cases was below 2.6 , while in $14.7 \%$ of cases it was greater than 5.1. The knee $(49.6 \%)$ and the wrist $(36.6 \%)$ were the most prevalent painful joints, and 375 patients complained of morning stiffness. The most frequent therapeutic regimens were prednisolone (81\%), methotrexate (62.4\%), hydroxychloroquine $(60.8 \%)$, sulfasalazine (24\%), and non-steroidal anti-inflammatory drugs (NSAIDs) (22.2\%). Based on the results of this study, the mean value of DAS-28 of $3.54 \pm 1.38$ implies disease activity in most cases in southeastern Iran. This indicates that changing therapy regimens is necessary.
\end{abstract}

Keywords: clinical manifestations, DAS-28, rheumatoid arthritis.

\section{Introduction}

Rheumatoid arthritis is a chronic systemic inflammatory disease with an unknown etiology. It is the most prevalent inflammatory arthritis. Different studies in developed countries have investigated its manifestations. QUEST-RA and an 8-year cohort study are two great studies in this field [1, 2]. Another study was conducted in 75 hospitals in France on both outpatients and inpatients [3]. Still other studies have been conducted in developing countries, including Turkey, Brazil, Malaysia, and Qatar [4-7]. It seems that the clinical manifestations of rheumatoid arthritis in terms of DAS-28 and functional class differ between developing and developed countries, such that the functional class has remained at a satisfactory level despite a high DAS-28 in developed countries [6]. However, extra-articular manifestations are less prevalent in Mediterranean countries [8].
There have been several registered studies in Iran concerning demographics and the clinical manifestations and activity of rheumatoid arthritis [9, 10]. This disease has a non-homogenous trend with different manifestations across the world, and there is little data about it in developing countries, including Iran. Therefore, this study was designed to assess its manifestations in the Sistan and Baloochestan province in southeastern Iran. The necessity of modifying treatment strategies and the need for biological medications can be assessed by investigating the specifications of this disease and promoting awareness of its activity in this region.

\section{Materials and Methods}

This is a descriptive, cross-sectional study in which samples were selected by convenience sampling. All cases referred to the Rheumatology Clinic of Ali Ebn

\footnotetext{
* Corresponding Author: Zahra Zakeri, Email: zah_zakeri@ yahoo.com, Tel: +98 9151410570
}

Received: 25 December 2016; Accepted: 29 February 2017 
Abitaleb Hospital in the time period of one year (October 2012 to October 2013). This study was approved by the Zahedan University of Medical Science Ethics Committee. All patients who were diagnosed with rheumatoid arthritis and fulfilled the American College of Rheumatology (ACR) and European League Against Rheumatism (ULAR) classification criteria for rheumatoid arteritis were selected for participation in the study by two rheumatologists. Data was collected by a trained nurse with direct supervision by the rheumatologists. The data registered in the patients' charts included: demographic information, duration of morning stiffness (any kind of discomfort experienced in the morning), highlighted pain zones on pictures, therapy regimen, functional class, rheumatoid nodules (confirmed by a rheumatologist), associated diseases such as hypertension (over 140/90) or consumption of anti-hypertensive drugs, hyperlipidemia with triglycerides $>200$, total cholesterol $\geq 200$, and LDL $\geq 130$ or consumption of anti-lipidemic drugs, and diabetes (FBS $\geq 126$ ) or consumption of anti-diabetic drugs.

DAS-28 values were investigated by a rheumatologist who recorded the number of swollen and tender joints.

Statistical analysis. All the information (raw data) collected from patients was saved in an Excel 2010 file (Microsoft Office, Microsoft, Washington D.C., USA). Data was presented as Mean \pm SD or frequency (Relative Frequency \%) for quantitative or qualitative variables, respectively. All statistical analyses were carried out using SPSS version 16 (SPSS Inc., IL, USA).

\section{Results}

This study assessed 500 cases occurring within one year, 437 of whom were female $(87.4 \%)$ and 63 were male $(12.6 \%)$. Information regarding the cases and some clinical manifestations is shown in Tables 1 and 2, respectively. The mean age of subjects was $48.78 \pm$ 13.97 years, and the mean duration of the disease was $7.28 \pm 7.14$ years. The mean DAS-28 value was investigated in 476 cases ( 24 cases were missed) and values ranged from 0.14 to 7.75 (average $=3.54 \pm 1.38$ ) (Table 3). Among the cases, 287 (57.4\%) and 154 $(30.8 \%)$ suffered from joint tenderness and joint swelling, respectively.

The knee $(49.6 \%)$, wrist $(36.6 \%)$, ankle $(27.8 \%)$, shoulder $(26.6 \%)$, proximal interphalangeal $(25.2 \%)$, metacarpophalangeal (18.2\%), elbow (14.6\%), metatarsophalangeal (12.4\%), neck (7.2\%), carpometacarpal (5.8\%), and distal interphalangeal $(4.4 \%)$ were the most frequently reported painful joints. Prednisolone (81\%), methotrexate (MTX) (62.4\%), hydroxychloroquine (HCQ) (60.8\%), sulfasalazine (SSZ) (24\%), and non-steroidal anti-inflammatory drugs (NSAIDs) (22.2\%) were the most frequent therapies. Table 4 shows the frequency of drug doses. During the study, 56 cases $(11.76 \%)$ with a DAS-28 value of $4.09 \pm$ 1.38 consumed no drug, while 63 cases $(13.23 \%)$ with a DAS-28 value of $3.94 \pm 1.21$ consumed a mix of MTX, SSZ and HCQ, and prednisolone. Furthermore, 137 (24.4\%), 129 (25.8\%), 60 (12\%), and 48 (9.6\%) cases suffered from hypertension, hyperlipidemia, diabetes, and thyroid dysfunction, respectively.

Table 1. Demographic data of patients with rheumatoid arthritis

\begin{tabular}{lcc}
\hline Feature & Number & \% \\
\hline Sex & & \\
Male & 63 & 12.6 \\
$\quad$ Female & 437 & 87.4 \\
Education & & \\
$\quad$ Illiterate & 285 & 57.00 \\
Primary school & 52 & 10.4 \\
Secondary school & 42 & 8.4 \\
Diploma & 68 & 13.6 \\
Other & 52 & 10.6 \\
Smoking & 67 & 13.4 \\
\hline
\end{tabular}

Table 2. Clinical and serological features of RA patients

\begin{tabular}{lcc}
\hline Feature & Number & \% \\
\hline Deformity & 72 & 14.4 \\
$\quad$ Hand & 55 & 11 \\
$\quad$ Foot & 3 & 0.6 \\
$\quad$ Both hand \& foot & 14 & 2.8 \\
Nodule & 13 & 2.6 \\
Functional class & & \\
$\quad$ I & & 14.8 \\
II & 74 & 73.6 \\
III & 368 & 10 \\
IV & 50 & 0.6 \\
$\quad$ Missing & 3 & 11 \\
Morning stiffness (minute) & 5 & \\
$\quad$ No & 125 & 25 \\
$<15$ & 172 & 34.4 \\
$\quad$ 15 60 & 121 & 24.2 \\
$>60$ & 82 & 16.4 \\
ESR (mm/h) & & \\
$>20$ (male) & 25 & 44.65 \\
$\quad \leq 20$ (male) & 31 & 55.36 \\
$>30$ (femaile) & 160 & 38.9 \\
$\leq 30$ (female) & 260 & 61.9 \\
Missed & 24 & 4.8 \\
\hline
\end{tabular}


Table 3. Disease activity score ESR DAS-28 in patients with rheumatoid arthritis

\begin{tabular}{lcc}
\hline Das-28 & Number & \% \\
\hline$<2.6$ & 144 & 30.25 \\
$2.6-3.2$ & 74 & 15.54 \\
$3.2-5.1$ & 188 & 39.50 \\
$>5.1$ & 70 & 14.71 \\
Missed & 24 & 4.8 \\
\hline
\end{tabular}

Table 4. Treatment regimens in RA patients

\begin{tabular}{lcc}
\hline Drug & Number & \% \\
\hline Prednisolone (mg/day) & 405 & 81 \\
$<2.5$ & 79 & 15.8 \\
$\quad 2.5-5$ & 251 & 50.2 \\
$>5$ & 75 & 15 \\
Methotrexate mg/week & 312 & 62.4 \\
$<15 \mathrm{mg}$ & 185 & 37 \\
$\quad 15-25 \mathrm{mg}$ & 127 & 25.4 \\
Hydroxychloroquine mg/day & 304 & 60.8 \\
$200 \mathrm{mg}$ & 284 & 56.8 \\
$\quad 400 \mathrm{mg}$ & 20 & 4 \\
Sulfasalazine gr/day & 120 & 24 \\
$<1$ & 35 & 7 \\
$>1.5$ & 85 & 17 \\
\hline
\end{tabular}

\section{Discussion}

This study was carried out by two rheumatologists in a provincial referral hospital in the southeast of Iran. The mean age of cases $(48.78 \pm 13.97$ years $)$ is consistent with other studies in developing countries [4-7], while it is about one decade lower than studies conducted in European and North American countries. This result, which is consistent with Asian and African reports, indicated that the mean age of patients with rheumatoid arthritis in Iran is lower than the mean age of patients in European and American countries [11].

In this study, $87.45 \%$ of participants were female and $12.55 \%$ were male rheumatoid arthritis patients; the ratio of female to male was $7: 1$. This is similar to Latin American countries (5.2:1) and South Africa (6.9:1), but it is higher than European countries and the USA where the ratio is $3: 1$ [11].

In the current study, the equivalent DAS-28 was 3.54, which is lower than that of Dubai (5.2) [12], France (4.9) [3], Algeria (4.3) [13], and Malaysia (4.28) [6] and higher than that of Qatar (2.91) [7]. The doses and timely consumption of drugs are important factors affecting DAS-28 [14]. Biological medications were not used in this study because of the poor economic status of this region and the lack of insurance coverage for drugs. In studies conducted in France and Qatar, however, $29 \%$ of cases received biologics. Corticosteroids were used by $81 \%, 72 \%, 72.7 \%$, and
$51 \%$ of cases in Iran, France, Malaysia, and Qatar, respectively. Methotrexate was used by $62.4 \%$, 45\%, $51.3 \%$, and $75 \%$ of cases in Iran, France, Malaysia, and Qatar, respectively. The lower DAS-28 of Qatar cases may originate from the higher consumption of methotrexate and other biologics.

In this study, $14.71 \%$ of cases had DAS-28 $\geq 5.1$, which is lower than Turkey $(52.1 \%)$ [4], while both countries selected cases from one center and a subspecialty clinic. In Turkey, $81 \%$ and $4 \%$ of cases consumed methotrexate and TNF blockers, respectively. According to Turkish authors, no access to timely treatment facilities is a cause for high DAS-28 values. This problem exists in the studied region too. Therefore, geographical and race differences should be taken into account in explaining differences in the results.

A part of disease activity assessment using DAS-28 is associated with the patients' perception of pain intensity. This is a subjective finding which depends on different factors, including education. In this study, 379 cases $(75.8 \%)$ had a minimal education ( $<12$ years). This result is consistent with Gladers' study where $77 \%$ of cases had a minimal education [15]. In Malaysia, $55.6 \%$ of cases had a minimal or no formal education [6]. Some studies have indicated the existence of a relationship between rheumatoid arthritis and a minimal education $[16,17]$. It should be noted that the education level of the patients affects their perception expressed by the visual analogue scale. The frequency of rheumatoid nodules in this study was $2.6 \%$. This is consistent with its frequency in Turkey (3.6\%), Malaysia (4.5\%), and Latin America (2.5\%) but differs from its frequency in Brazil (12.5\%). There is no justifiable explanation in the literature regarding this difference. Some authors have suggested that not paying accurate attention to the nodules may be considered a viable reason, but conducting more studies seems necessary.

The results of this study were extracted from one center, and this is a limitation of this study. This study was done in a referral center in the Sistan and Baloochestan province and covered a part of the southeast region of Iran, but patients with mild manifestations may not refer to this center and some patients referred to other nearby provinces. Therefore, the cases in this study may not represent all the patients of this province, and this necessitates the conducting of studies in multiple centers.

\section{Conclusion}

This study found a lower mean age of patients, higher 
female to male ratio, and lower prevalence of nodules in rheumatoid arthritis patients in southeastern Iran than in European and North American countries. These results are consistent with findings of other studies in developing countries. Moreover, the mean value of DAS-28 was 3.54 , implying the activity of this disease in most cases in southeastern Iran. This indicates the necessity of changing therapy regimens.

\section{Conflict of interest}

The authors declare no conflicts of interest.

\section{References}

1. Sokka T, Kautiainen H, Toloza S, Mäkinen $\mathrm{H}$, Verstappen SM, Hetland ML, et al. QUEST-RA: quantitative clinical assessment of patients with rheumatoid arthritis seen in standard rheumatology care in 15 countries. Annals of the Rheumatic Diseases 2007; 66(11): 1491-6. doi: 10.1136/ard. 2006.069252.

2. Thyberg I, Dahlström Ö, Björk $\mathrm{M}$, Arvidsson $\mathrm{P}$, Thyberg $\mathrm{M}$. Potential of the HAQ score as clinical indicator suggesting comprehensive multidisciplinary assessments: the Swedish TIRA cohort 8 years after diagnosis of RA. Clinical Rheumatology 2012; 31(5): 775-83. doi: 10.1007/s10067-02101937-0.

3. Sany J, Bourgeois P, Saraux A, Durieux S, Lafuma A, Daures J, et al. Characteristics of patients with rheumatoid arthritis in France: a study of 1109 patients managed by hospital based rheumatologists. Annals of the Rheumatic Diseases 2004 63(10): 1235-40. doi: 10.1136/ard.2003.013110.

4. Kobak S. Demographic, clinical, and serological features of Turkish patients with rheumatoid arthritis: evaluation of 165 patients. Clinical Rheumatology 2011; 30(6): 843-7. doi: 10.1007/s10067-011-1678-5.

5. Mota LMHd, Neto S, Burlingame R, Ménard HA, Laurindo IMM. Laboratory characteristics of a cohort of patients with early rheumatoid arthritis. Revista Brasileira de Reumatologia 2010; 50(4): 375-80. doi: $10.1590 / \mathrm{s} 0482-$ 50042010000400004 .
6. Teh C, Wong J. The pattern and clinical manifestations of rheumatoid arthritis in Sarawak General Hospital. Clinical Rheumatology 2008; 27(11): 1437-40. doi: 10.1007/s10067008-0945-6.

7. Lutf A, Poil AR, Hammoudeh M. Characteristics of patients with rheumatoid arthritis in Qatar: a cross-sectional study. International $J$ of Rheumatic Diseases 2014; 17(1): 63-5. doi: 10.1111/1756-185x.12135.

8. Erdes S, Alekseeva L, Krylov M, Kariakin A, Benevolenskaia L. [The prevalence of rheumatoid arthritis and the rheumatoid factor in the native inhabitants of northeastern Siberia]. Terapevticheskii Arkhiv 1998; 71(5): 9-12.

9. Davatchi F, Akbarian M Shahram F, Nadji A, Gharibdoost F, Jamshidi AR. DMARD combination therapy in rheumatoid arthritis: 5-year follow-up results in a daily practice setting. APLAR Journal of Rheumatology 2006; 9(1): 603. doi: 10.1111/j.1479-8077.2006. 00166.x

10. Mobini M. Probable risk factors of rheumatoid arthritis, a case control study. Journal of Mazandaran University of Medical Sciences 2010; 20(75): 38-44.

11. Lee DM WM. Rheumatoid arthritis. Lancet 2001

12. Badsha H, Kong KO, Tak PP. Rheumatoid arthritis in the United Arab Emirates. Clinical Rheumatology 2008; 27(6): 73942. doi: 10.1007/s10067-007- 0782-z.

13. Slimani S, Abbas A, Ammar AB, Kebaili D, Rahal F, Khamari MC, et al. Characteristics of rheumatoid arthritis in Algeria: a multicenter study. Rheumatology International 2014; 34(9): 12359. doi: 10.1007/s00296-014-29817.

14. Albers J, Paimela L, Kurki P, Eberhardt K, Emery P, van't Hof $M$, et al. Treatment strategy, disease activity, and outcome in four cohorts of patients with early rheumatoid arthritis. Annals of the Rheumatic Diseases 2001; 60(5): 453-8. doi: 10.1136/ard. 60.5.453.

15. Estel BAP ML, Wojdyla D, Acevedo E, Laurindo IMM, Guibert ZM. Is there something we can learn from rheumatoid arthritis in Latin America? A descriptive report on an inception Cohort of 1093 patients Ann Rheum Dis 2008; 67.

16. Bengtsson C, Nordmark B, Klareskog L, Lundberg I, Alfredsson L. Socioeconomic status and the risk of developing rheumatoid arthritis: results from the Swedish EIRA study. Annals of the Rheumatic Diseases 2005; 64(11): 1588-94. doi: 10.1136/ard.2004.031666.

17. Pedersen M, Jacobsen S, Klarlund M, Frisch M. Socioeconomic status and risk of rheumatoid arthritis: a Danish case-control study. The Journal of Rheumatology 2006; 33(6): 1069-74. 